\title{
Colonoscopy in Lynch syndrome: the need for a new quality score
}

\author{
Jurjen J. Boonstra ${ }^{1}$ - Wouter H. de Vos tot Nederveen Cappel $^{2}$ • \\ Alexandra M. J. Langers ${ }^{1} \cdot$ Hedwig van der Sluis ${ }^{2} \cdot$ James H. Hardwick $^{1}$. \\ Hans F. A. Vasen ${ }^{1}$
}

Published online: 9 November 2016

(C) Springer Science+Business Media Dordrecht 2016

\section{Dear Editor,}

Individuals with Lynch syndrome have a high lifetime risk of developing colorectal cancer (CRC) varying from 30 to $70 \%$, partly depending on the underlying mismatch repair (MMR) gene defect [1].

Adenomas are known to cause CRC (adenoma-carcinoma sequence) in the general population and polypectomy is documented to prevent CRC. More than 10 years ago, de Jong et al. [2] compared the incidence and features of adenomas between proven MMR-mutation carriers and family members that were found not to carry the gene defect. They reported a significantly increased incidence of adenomas in the mutation carriers compared to the controls. In addition, they found that adenomas in the mutation carriers showed more often high grade dysplasia and a villous architecture. Most adenomas as well as CRC in this group were located in the right colon. Moreover, about $50 \%$ of low grade adenomas and $100 \%$ of high grade adenomas showed loss of MMR-protein expression. A recent study reported that MMR-deficiency may even be present in macroscopically normal crypts [3]. These studies confirmed the role of adenomas in CRC development in Lynch syndrome.

Nearly twenty years ago, Järvinen et al. reported in the only controlled trial available that colonoscopic surveillance and polypectomy at 3 year intervals in Lynch

Hans F. A. Vasen

hfvasen@lumc.nl

1 Department of Gastroenterology and Hepatology, Leiden University Medical Centre, PO Box 9600, 2300 RC Leiden, The Netherlands

2 Department of Gastroenterology and Hepatology, Isala Clinics, Zwolle, The Netherlands syndrome lead to a decrease in CRC incidence [4]. However, several studies provided evidence that the adenomacarcinoma sequence in Lynch syndrome is accelerated and that (interval) CRCs may develop within 2 -3 years after a normal colonoscopy [5-7]. Based upon these observations, an intensive surveillance protocol is recommended with colonoscopy usually at 1-2 years intervals.

A recent study by the Mallorca group [8], provided estimates of cancer incidence in patients with Lynch syndrome under prospective cancer surveillance. A remarkable finding of this study was the frequent occurrence of colorectal cancer (CRC) despite colonoscopic screening with removal of adenomas. This observation raises questions about the effectiveness of colonoscopic surveillance. The authors speculate that "MMR mutation carriers are capable of producing CRC not only inside an adenoma but also independently of a macroscopically visible adenoma". Other explanations might be the accelerated carcinogenesis in Lynch syndrome or a different appearance of adenomas (e.g., flat adenomas) and CRC (small CRC) in Lynch syndrome that can be missed by a suboptimal colonoscopy. A study of interval cancers in Lynch syndrome patients registered at the Dutch Lynch syndrome registry, showed that factors associated with the development of interval cancers included incomplete investigation of the colon, insufficient cleaning of the colon and incomplete removal of adenomas during the previous examination [9]. It is clear that these findings and the observations of the Mallorca group warrant a high quality colonoscopy in Lynch syndrome patients.

In recent years, several quality parameters have been proposed to optimise colonoscopic examination in general $[10,11]$. These parameters include visualisation and documentation of the appendiceal orifice and ileocecal valve or intubation of the terminal ileum to ensure full inspection of 
the colon, adequate preparation of the colon as estimated by the BBPS (Boston Bowel Preparation Scale), documentation of the withdrawal time (which should be longer than $6 \mathrm{~min}$ ) and the Gloucester Comfort Scale (which estimates the examination burden for patients). While all of the above-mentioned parameters will certainly improve the quality of the colonoscopic examination, they do not necessarily provide a complete picture. While all parameters may be adequately met in a patient, in reality the quality of the colonoscopy can be impaired by factors not captured by these quality measurements. Examples of situations that may decrease quality include (1) a sigmoid that cannot be easily inspected due to spasms, (2) severe diverticulosis, (3) a fixed angulated sigmoid, (4) unresolvable loops, (5) painful colonoscopy that limits repeated inspection of specific areas of the colon, and (6) an unstable patient with severe bradycardia, hypotension or decreased oxygen saturation. As these factors are not routinely reported in the colonoscopy report, this crucial information is lost before it reaches the clinician who determines surveillance intervals at a later date in the outpatient clinic.

Extensive discussion of this issue among members of the CRC population screening team at the department of Gastroenterology \& Hepatology at Leiden University Medical Centre led to the development and implementation of a new subjective quality score, referred to as the 'Leiden Quality Score'. This score is based on the endoscopist's overall impression of the quality of the colonoscopy and an opinion on whether polyps may have been missed. The definition of the quality score is shown in Table 1.

What benefits might accompany implementation of the Leiden Quality Score (LQS)? The primary benefit of this simple new scoring system will be improved communication between the endoscopist and the clinician ordering the examination. The score should always be accompanied by information about the cause of a low LQS and advice on how a specific problem can be prevented during the next examination. The score is especially important in Lynch syndrome patients, but may also be important in familial CRC screening and other high-risk groups. In these patients, the screening interval might be shortened based on

Table 1 The Leiden Quality Score (LQS)

\begin{tabular}{lll}
\hline Score & Quality of examination & Description \\
\hline 5 & Very good & $>99 \%$ Certain no polyps missed \\
4 & Good & $>95 \%$ Certain no polyps missed \\
3 & Reasonable & $>90 \%$ Certain no polyps missed \\
2 & Moderate & $>80 \%$ Certain no polyps missed \\
1 & Inadequate & Only large polyps excluded \\
\hline
\end{tabular}

this score. For example, a LQS of 3 in a Lynch syndrome patient should result in a shortening of the surveillance interval from 2 years to 1 year, while a LQS score of 2 indicates that the colonoscopy should be repeated within 1 year.

In order to validate this scoring system, we have now implemented the LQS for all patients at risk of CRC undergoing colonoscopy. When 300 consecutive examinations have been completed, we will determine whether the LQS indeed improves communication between the endoscopist and the requesting clinician, and whether the LQS improves (documented) advice aimed at preventing specific problems during the next examination (e.g., alternative approaches to cleaning of the colon, propofol sedation, use of antispasmodics during endoscopy, etc.). We will also investigate whether this score led to adjustment of the screening interval in Lynch syndrome. We hope that implementation of this new quality parameter will improve the prevention of CRC in Lynch syndrome patients and other high risk groups.

Author contributions Design of manuscript: JJB, HFAV; writing of first draft of manuscript: JJB, WHVNC, HFAV; editing the first draft and approving the final draft of the manuscript: JJB, WHVNC, AMJL, HS, JHH, HFAV.

\section{Compliance with ethical standards}

Conflict of interest None.

\section{References}

1. Vasen HF, Tomlinson I, Castells A (2015) Clinical management of hereditary colorectal cancer syndromes. Nat Rev Gastroenterol Hepatol 12(2):88-97

2. De Jong AE, Morreau H, Van Puijenbroek M et al (2004) The role of mismatch repair gene defects in the development of adenomas in patients with HNPCC. Gastroenterology 126(1): $42-48$

3. Kloor M, Huth C, Voigt AY, Benner A, Schirmacher P, von Knebel Doeberitz M et al (2012) Prevalence of mismatch repairdeficient crypt foci in Lynch syndrome: a pathological study. Lancet Oncol 13:598-606

4. Järvinen HJ, Mecklin JP, Sistonen P (1995) Screening reduces colorectal cancer rate in families with hereditary nonpolyposis colorectal cancer. Gastroenterology 108(5):1405-1411

5. Vasen HF, Nagengast FM, Khan PM (1995) Interval cancers in hereditary non-polyposis colorectal cancer (Lynch syndrome). Lancet 345(8958):1183-1184 (519)

6. Lanspa SJ, Jenkins JX, Cavalieri RJ, Smyrk TC, Watson P, Lynch $\mathrm{J}$ et al (1994) Surveillance in Lynch syndrome: how aggressive? Am J Gastroenterol 89(11):1978-1980

7. Jass JR, Stewart SM, Stewart J, Lane MR (1994) Hereditary nonpolyposis colorectal cancer-morphologies, genes and mutations. Mutat Res 310(1):125-133

8. Møller P, Seppälä T, Bernstein I et al (2015) Mallorca Group (http://mallorca-group.eu). Cancer incidence and survival in Lynch syndrome patients receiving colonoscopic and 
gynaecological surveillance: first report from the prospective Lynch syndrome database. Gut. doi:10.1136/gutjnl-2015-309675

9. Haanstra JF, Vasen HF, Sanduleanu S et al (2013) Quality colonoscopy and risk of interval cancer in Lynch syndrome. Int J Colorectal Dis 28(12):1643-1649

10. Fayad NF, Kahi CJ (2014) Quality measures for colonoscopy: a critical evaluation. Clin Gastroenterol Hepatol 12(12):1973-1980
11. Rees CJ, Thomas Gibson S, Rutter MD, Baragwanath P, Pullan R, Feeney M, Haslam N; on behalf of: the British Society of Gastroenterology, the Joint Advisory Group on GI Endoscopy, the Association of Coloproctology of Great Britain and Ireland (2016) UK key performance indicators and quality assurance standards for colonoscopy. Gut. doi:10.1136/gutjnl-2016-312044 